Florida International University FIU Digital Commons

7-7-1999

\title{
The genetic and environmental effects of parental age on the expression of psychopathology in adoptees
}

Lyndon Joseph Aguiar

Florida International University

DOI: $10.25148 /$ etd.FI13101540

Follow this and additional works at: https://digitalcommons.fiu.edu/etd

Part of the Psychology Commons

\section{Recommended Citation}

Aguiar, Lyndon Joseph, "The genetic and environmental effects of parental age on the expression of psychopathology in adoptees" (1999). FIU Electronic Theses and Dissertations. 1088.

https://digitalcommons.fiu.edu/etd/1088 


\section{FLORIDA INTERNATIONAL UNIVERSITY}

Miami, Florida

THE GENETIC AND ENVIRONMENTAL EFFECTS OF PARENTAL AGE ON THE EXPRESSION OF PSYCHOPATHOLOGY IN ADOPTEES

A thesis submitted in partial fulfillment of the

requirements for the degree of

MASTER OF SCIENCE

in

PSYCHOLOGY

by

Lyndon Joseph Aguiar

1999 
To: Dean Arthur W. Herriott

College of Arts and Sciences

This thesis, written by Lyndon Joseph Aguiar, and entitled The Genetic and Environmental Effects of Parental Age on the Expression of Psychopathology in Adoptees, having been approved in respect to style and intellectual content, is referred to you for judgment.

We have read this thesis and recommend that it be approved.

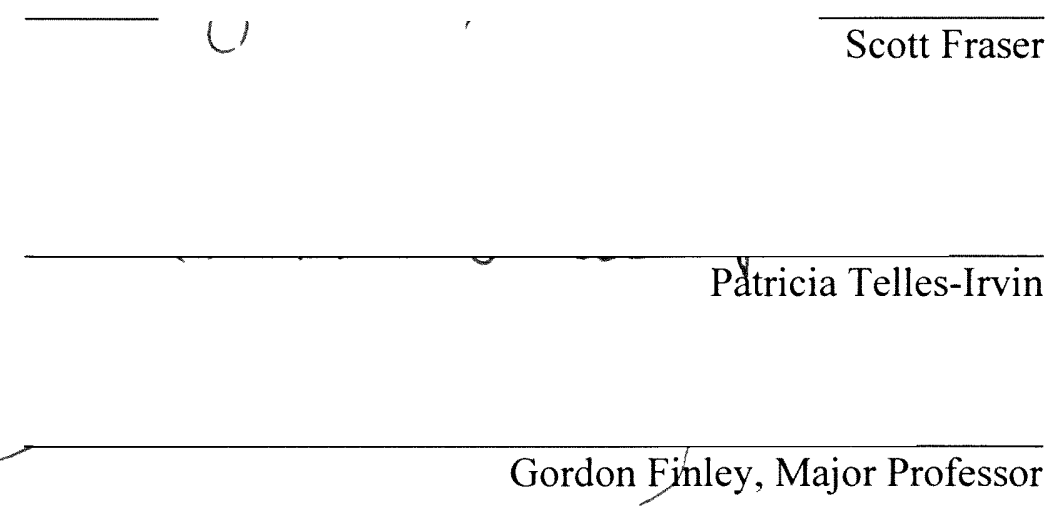

Date of Defense: July 7, 1999

This thesis of Lyndon Joseph Aguiar is approved.

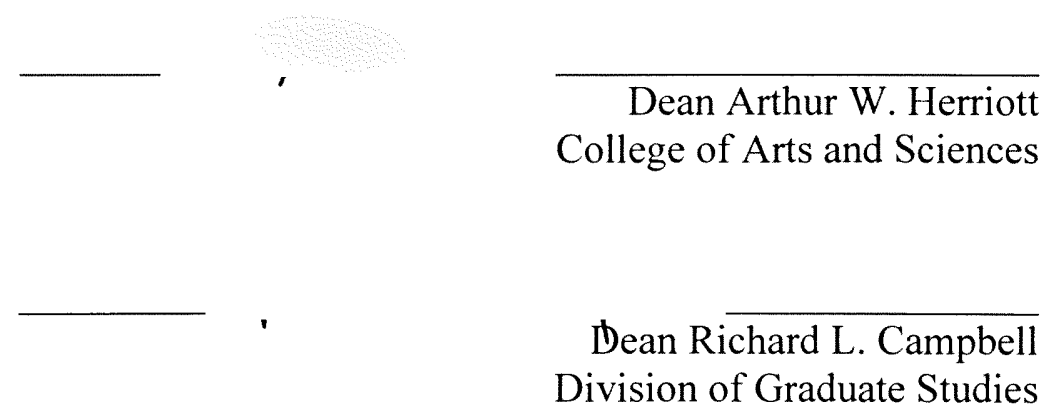

Florida International University, 1999 


\section{DEDICATION}

I dedicate this thesis to my wife, Sonia, who has provided me with the moral support, love, and patience to make this thesis a reality. 


\section{ACKNOWLEDGMENTS}

This research used the Iowa Adoption Studies, 1975-1982 data set [made accessible in 1988, machine-readable data files]. These data were collected by R. Cadoret available through the archive of the Henry A. Murray Research Center of Radcliffe College, Cambridge, Massachusetts (Producer and Distributor).

I would like to thank my major professor, Dr. Gordon Finley, for having the conviction in my abilities to develop a quality thesis. His guidance and support were instrumental in the completion of this thesis. 
THE GENETIC AND ENVIRONMENTAL EFFECTS OF PARENTAL AGE ON THE EXPRESSION OF PSYCHOPATHOLOGY IN ADOPTEES

\author{
by \\ Lyndon Joseph Aguiar \\ Florida International University, 1999 \\ Miami, Florida \\ Professor Gordon E. Finley, Major Professor
}

Secondary analysis of 581 adoptees was utilized to determine if parental age is related, either genetically or environmentally, to the development of psychopathology.

The significant results showed that proband adoptees (with psychopathology in biologic relatives) with younger birthparents had increased alcohol abuse and those with younger birthfathers had increased antisocial personality while adoptees with older birthparents had increased depression. Analyses on control adoptees (with background free of known genetic disturbances) showed that those with younger adoptive mothers had increased antisocial personality and drug abuse and those with younger adoptive fathers had increased antisocial personality while adoptees with older adoptive fathers had increased depression. 
Implications of these findings are that adoptees with both younger birth and adoptive parents are more likely to have externalizing symptoms, while adoptees with both older birth and adoptive parents are more like to have internalizing symptoms. This information is beneficial to those involved in adoption placement. 


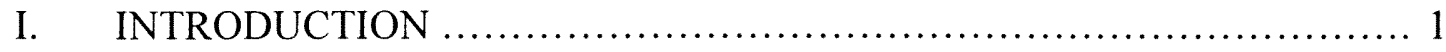

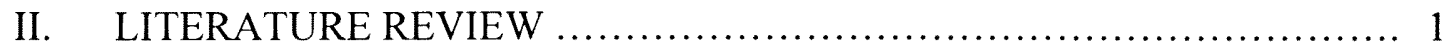

Parental Age ......................................................... 1

Genetic and Environmental Contribution to Psychopathology ............... 3

Research Problem ...................................................... 8

Hypothesis .......................................................... 9

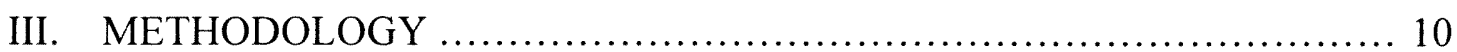

Source of Data and Subjects ......................................... 10

Criteria for Proband Selection ICFS Study ............................... 11

Criteria for Proband Selection LSS Alcohol Study ....................... 12

Criteria for Proband Selection LSS Antisocial Study .......................13

Criteria for Adoptee Psychopathology ................................... 14

Sample Size ....................................................... 15

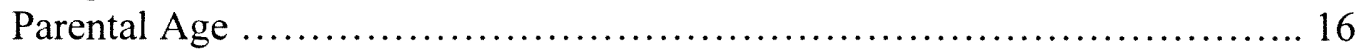

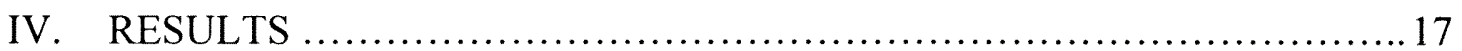

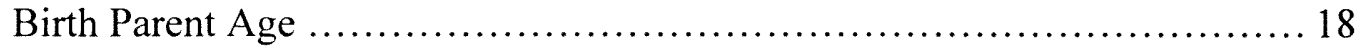

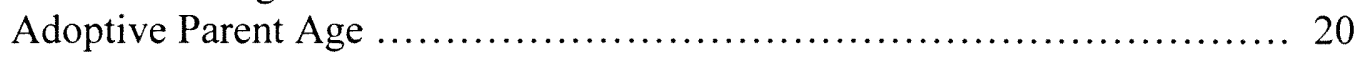

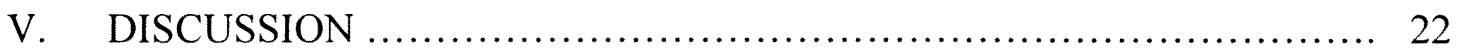

VI. CONCLUSION ..................................................... 25 


\section{Introduction}

What factors contribute to psychopathology in a child? Is there a predisposition to alcohol abuse, antisocial personality disorder, depression, or drug abuse? What role, if any, does genetics and/or environment have in the etiology of psychopathology? Does parental age at time of child's birth have any effect on the etiology of psychopathology?

This thesis examines parental age both as a genetic and environmental variable. Specifically, the age of birth parents will be assessed to determine genetic influences of age on the transmission of psychopathology to offspring. Environmental effects of parental age will be examined by assessing the effects of adoptive parents' age at time of adoption on psychopathology in adoptees. This issue has become increasingly relevant both because of the growing number of mothers who have children at a very young age and, the opposite, the many parents who opt to have children later in life. A secondary data analysis of a large adoption study will be employed to determine the possible role of parental age both as a genetic and environmental influence on psychopathology in adopted children. This information will provide insight to prospective adoptive parents who are concerned about the background of children whom they wish to adopt and risks they may be willing to assume.

Literature Review: Parental Age

There has been a considerable amount of research on the effects of parental age at parturition on various disorders in the child. Studies have shown that age of a parent at time of childbirth has an effect on the psychopathology of the child. The research in this area can be divided into three categories: 1) Studies that reveal psychopathology in the child is more likely to emerge in younger rather than older parents; 2) studies that show psychopathology in the child is more likely to emerge in older rather than younger 
parents; and 3) studies that exhibit no relationship between psychopathology in the child and age of parent.

The following studies reveal that children of younger parents are more likely to express psychopathology than children of older parents. Hechtman (1989) concluded that a higher incidence of psychiatric problems tended to be associated with children of adolescent mothers. Simonds and Aston (1982) found that children of mothers who gave birth before age 30 had significantly more emotional detachment and anxiety than children of older mothers. It was also found that decreased paternal age substantially increased the susceptibility to Alzheimer's disease (Farrer, Cupples, Connor, Wolf, \& Growdon, 1991).

Conversely, there are a number of studies that show that children of older parents are more likely to express psychopathology than children of younger parents. Increased parental age at parturition was associated with an increase in dyslexia in boys (Jayasekara \& Street, 1978), an increase in infantile autism (Gillberg, 1980), an increase in childhood psychoses (Mouridsen, Rich, \& Isager, 1993; Gillberg, 1982), and a decrease in need achievement (Falbo \& Richman, 1979). In an analysis of a large population of psychiatric patients, Hare and Moran (1979) discovered that the mean ages of mothers and fathers at time of patients' birth was significantly higher than the general population. Other research shows advanced parental age at subjects' birth may be a risk factor for dementia of the Alzheimer type (Urakami, Adachi, \& Takahashi, 1989). Note Urakami's conclusion directly contradicts the conclusion reached by Farrer et al. (1991) regarding Alzheimer's disease as previously mentioned. 
There are a handful of studies that belong to the third category. The following studies show no relationship between psychopathology in the child and parental age. There were no significant differences between the maternal ages of probands and controls in a study of schizophrenics (Fananas, Marti-Tusquets, \& Bertranpetit, 1989). Hofman and colleagues (1990) found that maternal and paternal age had no effect on Alzheimer's disease.

Although the research is sometimes contradictory, it appears that parents' age at time of their child's birth does affect the rate of expression of psychopathology and other maladies in the lifespan of their offspring. While it appears that parental age has an effect on child psychopathology, it is not clear how parental age affects the outcome. Does biology/genetics cause this effect or is it social/environment? Adoption studies allow one to study the effects of birth parent's age and adoptive parent's age independently.

Literature Review: Genetic \& Environmental Contributions to Psychopathology What role does heredity play in the etiology of psychopathology? Adoption studies permit the exploration of genetic and environmental contributions to psychopathology. Beginning in the 1960's, adoption studies were utilized to study the role of heredity in psychopathology. The heritability of alcohol abuse, antisocial personality, criminality, hyperactivity, and schizophrenia were demonstrated (Cadoret, 1990). In addition to defining genetic etiologic factors in psychopathology, adoption studies allowed one to delineate environmental factors while controlling for heredity. Adoption studies have been described as a superior methodological tool with which to assess the relative importance of heredity versus environment and the interaction of the two in the development of psychopathology (Cadoret, Cain, \& Grove, 1980). 
There are two different methodologies used in adoption studies. In the first type, adoptees who exhibit a particular behavior of interest are selected (probands). Then adoptees without the particular behavior are selected (controls) and matched to the probands. The next step involves identifying the same behavior of interest in both adoptive and birth parents. If birth parents displayed a higher rate of the behavior compared to adoptive parents, this would be considered evidence of a genetic factor. Conversely, if adoptive parents displayed a higher rate of the trait, this would be considered evidence of an environmental factor in the etiology of the trait. Additionally, the genetic status of the adoptee can influence psychopathology in the adoptive parents (Finley \& Aguiar, 1998).

In the second type of adoption study, adopted-away offspring of biological parents with a particular behavior or trait (probands) are compared to adopted-away offspring of biological parents without this behavior or trait (controls). Both probands and controls are followed up to assess incidence of the behavior of interest in the adoptee. Finding offspring of probands with a high occurrence of this trait compared to offspring of controls would suggest a genetic etiology for the trait. Cadoret (1990) speaks of the advantages of this second type of adoption study. Unlike the first method, probands are not selected for a particular trait; rather it is their biological parents who are selected for this trait. Cadoret argued that the first method would result in samples coming from a treated or otherwise identified sample. He discussed that this could lead to spurious identification of environmental factors that affect the behavior of interest.

Among the psychopathologies evaluated by adoption studies are antisocial personality, alcohol abuse, drug abuse, depression, anxiety disorders, schizophrenia, 
somatoform disorders, attention deficit disorder, and others. The present study focuses on the following four (4) psychopathologies: Alcohol abuse, antisocial personality, depression, and drug abuse.

Of the four psychopathologies mentioned above, the etiology of alcoholism has, by far, been the most extensively studied. Many factors, both genetic and environmental, are involved in the etiology of alcoholism. There is considerable evidence that genetic factors strongly influence the transmission of alcoholism in male offspring (Goodwin et al, 1973, 1974; Cadoret, et al. 1980; Cloninger, Bohman, \& Sigvardsson, 1981). In Goodwin's (1976) analysis, children of alcoholics are more likely to have alcohol problems than children of non-alcoholics, despite being separated from their alcoholic parents in early life. Bohman, Sigvardsson, and Cloninger (1981) also reported that female alcoholism was strongly influenced by genetic factors. Cadoret and Troughton (1988) identified the following independent pathways leading to alcohol abuse: 1) having a biologic parent with an alcohol problem;2) being placed in an adoptive family where a family member other than the adoptee has an alcohol problem; and 3) having a biological parent with antisocial behavior which leads to the development in the adoptee of antisocial personality disorder, a condition associated with early adolescent use of drugs and alcohol, thus predisposing the adoptee to the development of alcohol abuse.

The genetic and environmental risks of alcoholism can also lead to other psychopathologies. Studies show that children of alcoholics exhibited a higher rate of psychopathology and were at a higher risk for oppositional and conduct disorders than 
children of non-alcoholics (Reich, Earls, Frankel, \& Shayka, 1993). Alcoholism and antisocial personality, in particular, are found to be correlated. It was also found that "the combination of this genetic factor [antisocial personality] with an alcohol problem in the adoptive family resulted in a significant genetic-environmental interaction" (Cadoret, 1985, p. 172). Schuckit (1973) proposed the following three etiologic links between alcoholism and antisocial personality: 1) alcohol abuse is a symptom of antisocial behavior; 2) alcohol abuse leads to sociopathic behavior; and 3) a common etiologic factor underlies both alcoholism and sociopathy. The term "comorbidity" best describes the interactions of alcoholism and antisocial personality. Comorbidity refers to "the presence of any additional coexisting ailment in a patient with a particular index disease." (Merikangas, Rounsaville, \& Prusoff, 1992, p. 77).

Antisocial personality has come to be an important factor in today's society because of its association with drug abuse, crime, and alcohol abuse (Cadoret, Troughton, Bagford, \& Woodworth, 1990). Cadoret described antisocial personality as a chronic condition that manifests itself before age 15 and continues throughout adult life. It is characterized by repeated disturbances in interpersonal and social relations such as criminal activity, aggressiveness, and other failures of social responsibility. The etiology of antisocial personality is linked to both genetic and environmental factors (Roth \& Finley, 1998). Studies on the adopted away offspring of female felons confirmed that the offspring had a higher incidence of antisocial personality than controls who did not come from an antisocial background (Crowe, 1974). An environmental factor also played a role in Crowe's study. Adoptees that were exposed to an unfavorable environment in the 
adoptive home (such as divorce) had an even greater chance of exhibiting antisocial personality as adults then those who did not. Many other researchers also demonstrated that genetic factors strongly influence the transmission of antisocial personality in adopted away offspring (Bohman, Cloninger, Sigvardsson, et al., 1982; Mednick, Gabrielli, \& Hutchings, 1984). Cadoret and colleagues (1990) utilized adoption studies to conclude that antisocial behavior in a biological parent (including a criminal background) predicted an increase in the numbers of adoptee adolescent antisocial behaviors.

Another form of psychopathology that has not been studied as extensively as alcoholism and antisocial personality is depression. Depression (unipolar) is considered one type of affective disorder; manic-depression (bipolar) being the other. In a study of affective disorders, it was found that the incidence of depression was significantly higher in adopted away offspring of affective-disordered biological parents than offspring of adoptees whose biological parents had no diagnosis nor other psychiatric conditions (Cadoret, 1978). Mendlewicz and Rainer (1977) also employed an adoption study to support their claim that genetics has a strong influence in the transmission of affective disorder. Reviewing twin and adoption studies, Winokur (1991) favored genetic factors in the etiology of unipolar illness and bipolar disorder. Environmental factors also play an important role in the transmission of depression. Both primary and secondary depression are positively and significantly correlated with such environmental factors as alcohol problems in another family member in the home or death of adoptive parent before age 19 (Cadoret, O’Gorman, Heywood, \& Troughton, 1985). 
Of the psychopathologies mentioned, the etiology of drug abuse/dependence has been the least documented. As with the previously mentioned psychopathologies, the etiology of drug abuse is also linked with genetic and environmental factors. Merikangas et al. (1992) found that offspring of parents with drug abuse were twice as likely to develop this condition as opposed to offspring of parents without this condition. Cadoret (1992) concluded that there was a strong genetic factor in the transmission of drug abuse from a biological parent with substance abuse problem (including alcoholism). In this same study, Cadoret also determined that environmental factors also played a role in the etiology of drug abuse. Specifically, the presence of a sibling with antisocial personality (including drug abuse) in the adoptive home was associated with the initiation of drug use in adoptees.

Research Problem

Considering the premise that parental age at parturition has an effect on the psychopathology of the child and the fact that the etiology of psychopathology itself has both genetic and environmental factors, the next logical question is "what interaction exists among the above?" Answers to questions such as these would allow a prospective adoptive parent to be better informed about the risks associated with adopting a child from an adverse background. It could also alert adoption agencies to the potential risks of placing children with such disturbed backgrounds with adoptive families of a specific age group or family history. 
Hypotheses

Research on non-adoptive families that concerns the affective quality of parenting as a function of parental age shows that children of fathers in their 30 s reported both a higher affective quality of parenting and a greater acceptance than children of both younger and older fathers (Finley, 1998a; Finley, 1998b). Similarly, Finley and colleagues (1993) found that first-time fathers in their 30s reported more satisfaction and gratification from fathering as well as more child centered childrearing attitudes than both younger and older fathers. Older mothers were found to be more accepting than younger mothers (Finley, 1998a). Therefore, it is expected that the enhanced home environment of parents who give birth to children in their 30 s would mitigate the probability of psychopathology being expressed in the child. With this same assumption, it can also be hypothesized that children adopted by parents in their 30 s would also have a decreased chance of psychopathology when compared to both younger and older adoptive fathers. For adoptive mothers, there may well be a linear relationship.

This leads to the following two questions which are the core questions for this thesis. Is the age of a birth parent differentially related to the expression of psychopathology such as alcohol abuse, antisocial personality, drug abuse, and depression in adopted away offspring when there is genetic disposition to psychopathology in the adoptee? Is the age of an adoptive parent at time of adoption differentially related to the expression of psychopathology such as alcohol abuse, antisocial personality, drug abuse, and depression in an adoptee from a background free of genetic disturbances? As in the affective quality of parenting, is there an optimal age 
to adopt children to minimize the risk of psychopathology that may or may not be present in the genes or environment? This thesis will attempt to answer the above questions.

Method

Source of Data \& Subjects

This research used the Iowa Adoption Studies, 1975-1982 data set [made accessible in 1988, machine-readable data files]. These data were collected by R. Cadoret available through the archive of the Henry A. Murray Research Center of Radcliffe College, Cambridge, Massachusetts (Producer and Distributor). A total of 581 subjects were selected for Cadoret's "Adoption Study." Subjects were derived from one of two sources: The Iowa Children's and Family Service (ICFS) or Lutheran Social Services (LSS). The primary difference between the ICFS data and the LSS data is that the ICFS subjects were selected on the basis of psychiatric dysfunction in biological family members while the LSS subjects were based on antisocial and alcohol related problems in biological family members.

Adoption records dating from 1939 through 1965 for 1,646 adoptees from ICFS were searched for information about psychopathology in biological parents and other relatives of adoptees. The experimental group (probands) consisted of adoptees who met all of the following criteria: 1) One or both of the biological parents had a psychiatric condition or showed behavior consistent with a psychiatric condition; 2) the adoptee was separated at birth from the biological parent(s); 3) there was no further contact with biological relatives; and 4) the adoptee was eventually placed in a permanent home. For 
every adoptee proband with psychopathology in biological relatives, a control adoptee was selected without recorded psychopathology in biological relatives and matched for age and sex of adoptee and for age of biological mother at time of the adoptee's birth.

The adoption record was the only source of information for the diagnosis of psychopathology in the biological family of the proband adoptee. Dr. Cadoret reviewed the adoption record and used his clinical judgment to make a determination whether there was any psychopathology in the adoptee's biological family. Information about the biological mother was the most complete since adoption workers based the adoption records on a series of interviews with the biological mother. Information on the biological father, which frequently was missing, was usually obtained via adoption records from the biological mother's interview, her parents, and from the social work agency. Specific information that contributed to Dr. Cadoret's diagnosis of each type of psychopathology will be discussed in later sections.

Criteria for Proband Selection

ICFS Study

A total of 367 adoptees were selected as subjects from the Iowa Children's and Family Service (ICFS) Agency for Dr. Cadoret's study of psychopathology. Data for ICFS was collected between the years of 1975 and 1978. A follow-up interview was conducted in 1982 for those adoptees who had turned 18 since the initial interviews. 
In the ICFS study, data for adoptees under the age of 18 were collected by a child psychiatrist who conducted interviews with the adoptive parents. Criteria for childhood psychopathology were based on the Ninth Revision of the International Classification of Diseases (ICD-9). For adoptees 18 years of age or older, Dr. Cadoret's team attempted to interview the adoptee in addition to the adoptive parents. Cadoret conducted interviews with the adoptive parents concerning the health and adjustment of their adopted child (adoptee). The adoptive parent interview was composed of about 150 items dealing with adoptee's temperament, development, social adjustment, school achievement, drinking, and drug-taking behavior. Parents were also questioned about family drinking habits, psychiatric problems, and basic demographic information. The adoptee interview consisted of a brief social history and a structured psychiatric interview. This allowed for the diagnosis of alcohol abuse, drug dependence, antisocial personality, unipolar and bipolar affective disorder, hysteria, anxiety neurosis, obsessional neurosis, schizophrenia, and mental retardation. In most cases the Diagnostic Interview Schedule (DIS) or the Schedule for Affective Disorders and Schizophrenia (SADS-L) was administered to the adoptee. The diagnosis of psychopathology in adoptees over the age of 18 was based on criteria established by Feighner and colleagues (1972) and was made by a psychiatrist who was blind to the biological background of the adoptee.

\section{LSS Alcohol Study}

Subjects were also chosen from Lutheran Social Services (LSS) for two other substudies. Data for LSS was collected between the years of 1979 to 1982 . Social workers examined records of adoptions from the years 1938 through 1962, selecting adoptees who 
had been separated at birth from biological parents and eventually adopted by nonrelatives. For the first LSS study denoted "LSSALC", adoption records were evaluated to determine if either biological parent had an alcohol problem. Adoptees with evidence of alcohol problems in biological family members served as the experimental group (probands) for the LSSALC study. An adoptee was placed in the experimental group when the adoption records showed that a biological relative was described as a "heavy drinker" with one or more social, legal, work, or medical problems due to drinking, or if the relative had been hospitalized for treatment of alcohol abuse. A total of 118 adoptees were selected as subjects for a study on alcohol abuse. Of this total, 59 control adoptees (half of the total) had no evidence of alcohol problems in biological family members, while the remaining 59 adoptees (probands) had evidence of alcohol problems in biological family members.

\section{LSS Antisocial Study}

A total of 96 adoptees from Lutheran Social Services were selected as subjects for a study of antisocial behavior. Adoptees with evidence of antisocial problems in biological relatives were considered probands in this second LSS study denoted "LSSA." Adoption records of adoptees in the experimental group (probands) indicated that biological relatives had one (1) or more of the following antisocial problems: School behavior problems, running away overnight, incorrigibility, staying out at night beyond permitted time, associating with children of bad reputation, reckless behavior, truancy, vandalism, stealing, using vulgarities, negative training school record, juvenile court record, police trouble, poor work history, marital problems, repeated fighting, sexual promiscuity, 
vagrancy, use of aliases, being a convicted felon, participation in rape or incest, excessive sex talk or play or self-exposure, and having a prison record. There were a total of 48 adoptee subjects that were considered probands in this study. The remaining 48 were considered control subjects because they had no evidence of antisocial personality in their biological relatives.

All three sub-studies were coded, collected, and analyzed using Statistical Package for Social Sciences (SPSS). An SPSS file was created for each of the aforementioned sub-studies. A fourth SPSS file, named "OTHER", served as a compilation of information from all three sub-studies. All of the present analyses were based on data found in the OTHER file.

Criteria for Adoptee Psychopathology

Cadoret distinguished psychopathology of various types in his data. For the purposes of this thesis, only the following four conditions in the adoptee will be discussed: Alcohol abuse, antisocial behavior, drug abuse, and depression. These conditions will serve as the dependent variables for the analyses of parental age and psychopathology in adoptees.

Adoptees were diagnosed with alcohol abuse when there was a hospitalization for alcohol detoxification or when there were two or more social or medical complications as a result of alcohol use as described by Feighner et al. (1972). The alcohol abuse was 
termed "primary" if it occurred without any other psychiatric conditions and "secondary" when it did. A total of 89 adoptees were diagnosed as alcoholic.

In his analysis, Cadoret used the DSM-III-R criteria for diagnosing antisocial personality in adoptee and adoptive parents. Again, interviews with adoptee and adoptive parent were utilized. A total of 63 adoptee subjects met the criteria for antisocial personality.

The diagnosis of drug abuse was discerned from interviews with adoptee and adoptive parent. Adoptive parents were questioned about the drug usage of their adopted child. Similarly, adoptees were interviewed and were asked specific questions about type of drugs used and frequency of use. Only adoptees from the LSS and ICFS data sets who were interviewed were considered as subjects in this study. Cadoret felt that without the interview, the criteria for Drug Abuse under the DSM IIIR would not be met. A total of 41 adoptee subjects were diagnosed with drug abuse.

A diagnosis of depression in the adoptee was given following interviews with the adoptee and his/her adoptive parents. The adoptees received either a structured psychiatric interview, the DIS, or the SADS-L. A total of 51 adoptee subjects met the criteria for depression. Research assistants who were blind to the adoptee's biologic background conducted all interviews. Again, Dr. Cadoret (psychiatrist) made the final diagnosis of depression based on the interviews and his clinical experience. Dr. Cadoret was similarly blind to the adoptee's biological background. 


\section{Sample Size}

The diagnosis of psychopathology in adoptee, whether it is alcohol abuse, antisocial personality, drug abuse, or depression was based on either structured interviews with the adoptee and the adoptive parents or with the adoptive parents alone. Diagnoses of psychopathology in adoptees under the age of 18 was based solely on the adoptive parent's interview. Adoptee subjects can be separated into one of three groups: 1) Adoptees under the age of 18 who were not interviewed, 2) adoptees over the age of 18 who were not interviewed, and 3) adoptees over the age of 18 who were interviewed. Concern arose as to whether accurate diagnoses were made for subjects who were not interviewed directly. Furthermore, it was determined that the adoptee's age as well as the amount of information obtained via interviews affected each dependent variable in unique ways.

In order to resolve this problem, analyses were conducted on each dependent variable separately to determine levels of positive diagnoses in each of the three age/interview status groups previously mentioned. Analyses were completed first for the full sample of 581 subjects, then control subjects only, and finally proband subjects only. If at least two subjects were diagnosed for a particular dependent variable and age/interview status group (e.g. 10-17 year old adoptees with antisocial personality) then subjects in that group were included in all subsequent analyses of that particular dependent variable. The analyses of the full sample, controls subjects only, and proband subjects only, yielded the following identical conclusions. The full sample (adoptees interviewed and not interviewed, regardless of age) could be used for the analyses of antisocial personality in adoptee. Adoptees who were 18 years and older (regardless of interview) could be used for the analyses of alcohol abuse. Finally, only adoptees who were interviewed could be used for analyses of drug abuse and depression. 


\section{Parental Age}

Dr. Cadoret's data contained information regarding age of adoptee's biological mother and sometimes of the biological father at time of birth of the adoptee. The data also contained the age of the adoptee as well as the age of the adoptive parent at the time of the interview. However, there was no variable that indicated the age of the adoptive parent at time of placement. This variable was calculated by subtracting the age of the adoptee at time of interview from the age of the adopted parent at time of the interview. The new variables of age of adopted mother at time of adoption (MAGEADOP) and age of adopted father at time of adoption (FAGEADOP) were added to the "OTHER" SPSS file previously mentioned.

Results

The chi-square method of analysis was used to test for significance. In cases where there are low numbers of subjects, Fischer's Exact test was utilized to assess significance. Data on biological fathers is known to be modest due to the nature of adoption and the adoption process. For example, nearly $30 \%$ of data on biological father's age is missing from the "OTHER" file. Even this figure is small compared to $70.7 \%$ of missing data for biological father's occupation and $74.5 \%$ of missing data for biological father's education (both in the "OTHER" file). In some cases, the data for psychopathology in biological parents and/or adoptee may be low because of underreporting. Even given these limitations, the analyses are viable because of the overall sample size.

Controls and probands were analyzed separately to differentiate adoptees with disturbed biological backgrounds (probands) from adoptees with no evidence of psychopathology in their biological background (controls). For the purpose of this study, 
two sets of independent variables were employed to determine the effect that parental age has on psychopathology. These two sets are 1) biological parent's age at birth of child with subsets of a) biological father's age and b) biological mother's age; and 2) adoptive parent's age at time of adoption with subsets of 1) adoptive father's age and 2) adoptive mother's age. Proband subjects (from disturbed biological backgrounds) were used in the analyses of birth parent age to determine the combined effects of genetic influences and parental age on psychopathology in the adopted-away child. Similarly, control subjects (no genetic disturbances in biological background) were used for the analyses of adoptive parent age to determine the purely environmental influences, if any, of parental age on psychopathology in the child.

Initially, the data were reviewed to determine basic trends of psychopathology in each individual age category. From this, basic age groupings were developed that roughly corresponded to societal and developmental stages of maturity. A set of age groupings was developed for each dependent variable separately. Eventually, these age groupings were reduced to two sets of age groupings for each of the following data groups: Birthfather, birthmother, adoptive father, and adoptive mother.

\section{Biological Parents Age}

Biological parents' data yielded the most significant results. Please refer to Tables 1 and 2 for the results of this section. When selecting adoptees from biologically disturbed backgrounds, one would expect these probands to exhibit a higher incidence of psychopathology as a result of these disturbances being transmitted genetically from the biological parents to the adoptees compared to controls who do not have these disturbances in their genetic background. The dependent variables: Alcohol Abuse, 
Antisocial Personality, Drug Abuse, and Depression in adoptee were analyzed against birth parents age.

The following results were derived from analyses using subjects selected from biologically disturbed backgrounds only (probands). Birth father's age was analyzed independently from birth mother's age. As expected, it was found that the rates of certain types of psychopathology were differentially related to the birth parent's age. Specifically, proband adoptees with young birthfathers (age 13-17) had a significantly higher rate of alcohol abuse compared to proband adoptees with birthfathers age 18 and over, $\chi^{2}(1, \underline{N}=186)=6.41, \underline{p}=.011$ (see Table 1). Similarly, proband adoptees with young birthfathers also showed significantly elevated rates of antisocial personality compared to adoptees born to older birthfathers, $\chi^{2}(1, \underline{N}=209)=4.21, p=.04$.

A very different trend was noted for the transmission of depression. Proband adoptees born to older birthfathers (age 41-62) had a significantly higher rate of depression than proband adoptees with birthfathers in the younger groups (age 13-17, 18$31,32-40), \chi^{2}(3, \underline{N}=159)=9.81, p=.02$. A non-significant result was found for the rates of drug abuse in adoptees with birthfathers of differing ages, $\chi^{2}(1, \underline{N}=159)=0.67$, $\mathrm{p}=.414$.

Reviewing Table 2 results for birthmother age, a pattern similar to birthfather age appears for the dependent variable Depression. While not significant, a linear relationship is apparent with proband adoptees born to the oldest birthmothers (age 3342) having the highest rate of depression when compared to proband adoptees born to younger birthmothers (age 13-17, 18-27, and 28-32), $\chi^{2}(3, \underline{N}=229)=5.76, p=.124$. By combining these four age groups into two, it is clear that adoptees born to older 
birthmothers (aged 28-42) have a significantly higher incidence of depression compared to adoptees born to younger birthmothers (age 13-27), $\chi^{2}(1, \underline{N}=229)=4.40, p=.036$.

Proband adoptees with birthmothers age 28-32 have a significantly elevated risk of alcohol abuse versus proband adoptees from birthmothers in other groups (ages 13-17, $18-27$, and 33-42), $\chi^{2}(3, \underline{N}=269)=7.93, p=.048$. Interestingly, however, adoptees born to the youngest birthmothers (age 13-17), like adoptees born to the youngest birthfathers, also had an elevated risk of alcohol abuse. Non-significant results were found for Antisocial Personality in adoptee and birthmother age, $\chi^{2}(3, \underline{N}=301)=0.72, p=.397$, and Drug Abuse in adoptee and birthmother age, $\chi^{2}(1, \underline{N}=229)=1.48, \mathrm{p}=.223$.

Adoptive Parents Age

The second set of analyses compared adoptive parent's age at time of adoption versus the expression of antisocial personality, drug abuse, alcohol abuse, and depression in the adoptee. For these analyses, control subjects (adoptees from backgrounds free of any known genetic disturbances) were chosen to examine the purely environmental effect, if any, of adoptive parental age on the expression of psychopathology in the adoptee. Using control subjects allows one to rule out genetic influences because there is no known genetic risk for psychopathology associated with these subjects. Further, there is no shared genetic heritage between the adoptees and the adoptive parents.

Please refer to Tables 3 and 4 for the results of this section. As in the previous section, adoptive mother's age at time of adoption is analyzed independently from adoptive father's age at time of adoption. As seen in Table 3, adoptees free of genetic disturbances (controls) with younger adoptive mothers (age 21-31) were more likely to have antisocial personality compared to control adoptees who had older adoptive mothers 
(age 32-47), $\chi^{2}(1, \underline{N}=264)=6.69, \mathrm{p}=.010$; Fisher's Exact Test $=.009$ (1-sided). A similar pattern was noted for Drug Abuse with adoptees with younger adoptive mothers (age 2131) having a significantly higher rate of drug abuse versus adoptees with older adoptive mothers (age 32-47), $\chi^{2}(1, \underline{N}=200)=4.32, \mathrm{p}=.038$; Fisher's Exact Test $=.037$ (1-sided).

No significant relationship was found between adoptee Alcohol Abuse and age of Adoptive Mother at time of adoption, $\chi^{2}(1, \underline{N}=218)=1.28, \mathrm{p}=.258$, Fisher's Exact Test $=.178$ (1-sided). A near significant relationship was noted between adoptee Depression and Adoptive Mother's Age at adoption with individuals with older adoptive mothers (age 32-47) having a higher rate of depression compared to individuals with younger adoptive mothers (age 21-31), $\chi^{2}(1, \underline{N}=200)=3.28, p=.070$; Fisher's Exact Test $=.057$ (1-sided). This result is very similar to the significant finding of increased depression in adoptees born to older biological mothers previously mentioned.

Table 4 shows the results of adoptive father's age and adoptee psychopathology for adoptees from backgrounds free of genetic disturbances (controls). It was found that adoptees with younger adoptive fathers (age 22-30) had significantly higher rates of antisocial problems compared to adoptees with older adoptive fathers aged 31 to $51, \chi^{2}(1$, $\underline{\mathrm{N}}=249)=4.44, \mathrm{p}=.035$; Fisher's Exact Test $=.039$ (1-sided). There was no significant difference between the incidence of drug abuse in adoptees with younger adoptive fathers (age 22-30) and older adoptive fathers (age 31-51), $\chi^{2}(1, \underline{N}=187)=1.56, p=.211$; Fisher's Exact Test $=.180$ (1-sided). Similarly, there was no relationship between adoptive fathers age and adoptee alcohol abuse, $\chi^{2}(1, \underline{N}=203)=0.89, \underline{p}=.347$; Fisher's Exact Test $=.237$ (1-sided). 
Adoptee Depression is clearly connected to adoptive father's age with adoptees with older adoptive fathers (age 31-51) having a significantly higher incidence of Depression compared to adoptees with younger adoptive fathers (age 22-30), $\chi^{2}(1$, $\underline{N}=187)=6.62, p^{=} .010 ;$ Fisher's Exact Test $=.005(1$-sided $)$. This result closely mimics the near significant outcome previously mentioned of increased adoptive mother's age leading to higher rates of adoptee depression.

\section{Discussion}

The results show clearly that parental age does play a role in the genesis and development of psychopathologies such as alcohol abuse, antisocial personality, drug abuse, and depression. For alcohol abuse, parental age appears to have a genetic effect because children with genetically disturbed backgrounds who are born to younger birth parents and given up for adoption exhibit a higher rate of alcohol abuse compared to children from the same disturbed backgrounds who are born to older birth parents. This same trend is noted for the expression of antisocial personality in children of younger birthfathers versus older birthfathers. There was no relationship found for birthmother age and the expression of antisocial personality in adoptee.

The implications of these finding are that prospective adoptive parents need to pay close attention to the age of the birth parents of the child they are adopting. This is especially true if the adopted child comes from a genetically disturbed background. The dynamics of personality and genetics of younger birth parents differ from that of older parents and these differences are transmitted genetically to the child thereby affecting the child's risk of psychopathology (Finley \& Aguiar, 1999). This information may allow the prospective adoptive parents to have an increased awareness of this tendency and thereby attempt early interventions. 
It can be hypothesized that individuals who engage in sexual intercourse at an earlier age (resulting in unwanted pregnancies) may have stronger tendencies to psychopathology such as alcohol abuse and antisocial personality. This increased risk of psychopathology is then transmitted genetically to the child given up for adoption. Considering that all subjects in this sample came from genetically disturbed backgrounds, we know that the older parents who gave up their children for adoption also had some form of psychopathology in their backgrounds. However, the risk for psychopathology such as alcohol abuse and antisocial personality in the offspring of older birth parents was not seen. Rather, the adoptees born to older birthparents were at risk of depressive symptoms.

Another theory is that the differing reasons individuals have for giving their child up for adoption may vary across age groups. For example, younger birth parents (in this sample) may have decided to relinquish their child because of the upheaval in their lives due to their alcohol abuse and antisocial personalities. On the other hand, an older birth parent may have chosen to relinquish for totally different reasons such as lack of financial support, other children in the home, social censure, career involvement, or perhaps feeling that they could not cope with parenting as a result of their psychopathology (depression). While both samples for birth parent age analysis came from genetically disturbed backgrounds, the younger group may have had a greater tendency to psychopathology such as alcohol abuse and antisocial personality thus transmitting this to their adopted away child while the older birthparents transmitted depression. Both alcohol abuse and antisocial personality can be considered externalizing symptoms of psychopathology. 
The results for the outcome of depression show that increasing birth parent age leads to significantly higher rates of depression in adopted away children. This finding was consistent for both older birthfathers and older birthmothers; with the trend in birthmothers being quite linear. Again, the psychological framework of an individual who opts to give up a child later in life may be indicative of a personality that has a stronger tendency to depression. Depression is considered to be an internalizing symptom of psychopathology that may have a genetic etiology. This increased tendency to depression may be transmitted to the child given up for adoption.

The analysis of adoptive parents age at time of adoption show that there is a relationship between the age of the adoptive parent and the expression of adoptee psychopathologies such as antisocial personality, drug abuse, and depression. Please note that adoptees with family backgrounds free of measured psychopathology were selected for the control analyses. The rate of alcohol problems in adoptee were not related to adoptive father's age nor adoptive mother's age (in separate analyses). Similarly, adoptive father age data yielded no significance for adoptive father age versus drug problems in adoptee.

Interestingly, however, adoptive mother data shows a strong significance between adoptive mother's age and the presence of antisocial personality in adoptees with younger versus older adoptive mothers. This same trend was noted for younger adoptive mothers having adoptees with higher rates of drug abuse compared to adoptees with older adoptive mothers. Both antisocial personality and drug abuse can be considered externalizing symptoms of problems in the adoptee. 
As stated earlier, affective quality of parenting as perceived by the parent and child is at its peak for fathers giving birth in their $30 \mathrm{~s}$. The enhanced parenting experience of adoptive parents choosing to adopt in their 30 s may have a similar effect on adoptees thereby minimizing the risk for such psychopathology as antisocial personality and drug abuse in the adoptee.

Contrary to the aforementioned studies on affective quality of parenting, the results showed that depression is more frequent in adoptees with older adoptive parents. Adoptees free of genetic disturbances had higher levels of depression if they had an older adoptive father compared to adoptees who had younger adoptive fathers. Adoptive mother data also showed a near significant relationship between adoptive mother's age and depression in the adoptee with adoptees with older adoptive mothers having the highest risk of depression compared to adoptees with younger adoptive mothers. Strikingly, the same trend was noted for adoptees with older birthparents having the greatest tendency to depression versus adoptees who had younger birthparents. It is unclear why psychopathology such as depression follows a different pathway compared to antisocial personality and drug abuse. Depression can be indicative of internalizing problems in the adoptee. Again more research is needed in the personality dynamics of older adoptive parents before a connection can be made.

\section{Conclusion}

Considering that this study utilizes data from adoptions occurring between the 1950 s and in the 1960s, we can expect that the societal mores were very different than they are today. The social stigma for having children out of wedlock was much greater in the 1950s and 1960s. This could also explain the paucity of data collected on biological fathers. Contemporary studies on parental age may yield different results. 
Another limitation of this study is that all subjects were selected from predominantly white rural areas of mid-western USA (Iowa). Different results may have been obtained if subjects were chosen from racially diverse urban areas or other countries. The personality traits of individuals choosing to live in rural areas may be different from those choosing to live in urban or suburban areas. Socioeconomic factors may come into play when subjects come from exclusively rural areas.

It can be concluded that parental age does have an effect on the expression of psychopathology in children. It is interesting to note that this effect on psychopathology has both a genetic and environmental etiology. Adoptees with both younger birth and adoptive parents were more likely to exhibit externalizing symptoms of psychopathology such as alcohol abuse and antisocial personality. By contrast, adoptees with both older birth and adoptive parents were more likely to exhibit internalizing symptoms of psychopathology such as depression. It can be theorized that the results for genetic effects are simply manifestations of personality traits that are prevalent in individuals who choose to have children at different ages. These personality traits are in turn genetically transmitted to offspring. It is conceivable that these personality traits are linked to various psychopathologies. Further investigation is needed to determine the relationship, if any, between psychopathology and personality traits.

What does this all mean to the prospective adoptive parent? The results of this research indicate that an adopted away child with a biological background of externalizing conditions such as alcohol abuse and/or antisocial personality is likely to exhibit these conditions if their birth parents are younger (less than age 18). Similarly, an adopted child without a known biological background of externalizing conditions such as 
antisocial personality and drug abuse is likely to exhibit these conditions if their adoptive parents are younger (less than age 30 at time of child's adoption). Both findings point to the inverse relationship between parent age and level of externalizing conditions in the child.

The results of this research also indicate that adopted away children with a biological background of psychopathology are more likely to exhibit an internalizing condition such as depression if their birth parents are older (age 41 and over for birth fathers and 28 and over for birth mothers). As with the results for externalizing conditions, the effect for adoptive parent's age mimicked the birth parent age effect. Adoptees with no known psychopathology in their biological background are more likely to exhibit internalizing conditions if their adoptive parents are older (age 31 and over at time of adoption). Here we find a direct relationship between parent age and level of internalizing conditions in the child.

These findings have possible policy implications in that the current practice of placing healthy adoptees with generally younger adoptive parents may have to be looked at more closely. The risk of the adoptee developing externalizing conditions when placed with younger adoptive parents has to be weighed against the risk of the adoptee developing internalizing conditions if placed with older adoptive parents. In addition, the more information regarding the adoptee's birth family (especially birth parent age and evidence of psychopathology) that is made available to the prospective adoptive parents, the better able they will be to assess and anticipate the possible risks of the adopted child developing a psychopathology. 
Overall, there is a dearth of research on parental age effects on children. Many of the studies that were found on parental age cover the physiological and behavioral consequences of children born to parents of differing ages. With the exception of Finley and colleagues, few researchers have delved into the effects of parental age on the emotional and psychological well being of children. With the alarming increase of individuals having children at a very young age or the opposite, choosing to have children much later in life, issues of parental age effects will only increase in importance. 
Table 1

Birthfather Age at Parturition and the Development of Psychopathology in Adoptees

\section{Adoptee Alcohol Abuse}

\begin{tabular}{lcc} 
Birth Father Age & Absent & Present \\
\hline $13-17$ & $9(53 \%)$ & $8(47 \%)$ \\
$18-62$ & $135(80 \%)$ & $34(20 \%)$ \\
\hline
\end{tabular}

$\chi^{2}(1, \underline{N}=186)=6.41, p=.011$

Adoptee Antisocial Personality

\begin{tabular}{lcc} 
Birth Father Age & Absent & Present \\
\hline $13-17$ & $12(67 \%)$ & $6(33 \%)$ \\
$18-62$ & $163(85 \%)$ & $28(15 \%)$ \\
\hline
\end{tabular}

$\chi^{2}(1, \underline{N}=209)=4.21, \mathrm{p}^{=} .040$

\section{Adoptee Drug Abuse}

\begin{tabular}{lcc} 
Birth Father Age & Absent & Present \\
\hline $13-17$ & $12(80 \%)$ & $3(20 \%)$ \\
$18-62$ & $126(88 \%)$ & $18(12 \%)$ \\
\hline
\end{tabular}

$\chi^{2}(1, \underline{N}=159)=0.67, \mathrm{p}=.414$

\section{$\underline{\text { Adoptee Depression }}$}

\begin{tabular}{lcc} 
Birth Father Age & Absent & Present \\
\hline $13-17$ & $13(87 \%)$ & $2(13 \%)$ \\
$18-31$ & $102(86 \%)$ & $16(14 \%)$ \\
$32-40$ & $17(100 \%)$ & $0(0 \%)$ \\
$41-62$ & $5(56 \%)$ & $4(44 \%)$ \\
\hline
\end{tabular}

$\chi^{2}(3, \underline{N}=159)=9.81, \mathrm{p}=.020$ 
Table 2

Birthmother Age at Parturition and the Development of Psychopathology in Adoptees

\begin{tabular}{lcc}
\hline & \multicolumn{2}{c}{ Adoptee Alcohol Abuse } \\
Birth Mother Age & Absent & Present \\
\hline $13-17$ & $50(76 \%)$ & $16(24 \%)$ \\
$18-27$ & $129(82 \%)$ & $29(18 \%)$ \\
$28-32$ & $15(60 \%)$ & $10(40 \%)$ \\
$33-42$ & $18(90 \%)$ & $2(10 \%)$ \\
\hline
\end{tabular}

$\chi^{2}(3, \underline{N}=269)=7.93, p=.048$

\section{Adoptee Antisocial Personality}

\begin{tabular}{lcc} 
Birth Mother Age & Absent & Present \\
\hline $13-17$ & $59(82 \%)$ & $13(18 \%)$ \\
$18-42$ & $197(86 \%)$ & $32(14 \%)$ \\
\hline
\end{tabular}

$\chi^{2}(1, \underline{N}=301)=0.72, p=.397$

\section{Adoptee Drug Abuse}

\begin{tabular}{lcc} 
Birth Mother Age & Absent & Present \\
\hline $13-17$ & $48(84 \%)$ & $9(16 \%)$ \\
$18-42$ & $155(90 \%)$ & $17(10 \%)$ \\
\hline
\end{tabular}

$\chi^{2}(1, \underline{N}=229)=1.48, p=.223$

\section{Adoptee Depression}

\begin{tabular}{lcc} 
Birth Mother Age & Absent & Present \\
\hline $13-17$ & $53(93 \%)$ & $4(7 \%)$ \\
$18-27$ & $116(89 \%)$ & $15(11 \%)$ \\
$28-32$ & $18(82 \%)$ & $4(18 \%)$ \\
$33-42$ & $14(74 \%)$ & $5(26 \%)$ \\
\hline
\end{tabular}

$\chi^{2}(3, \underline{N}=229)=5.76, p=.124$ 
Table 3

Adoptive Maternal Age at Adoption and the Development of Psychopathology in Adoptees

\section{Adoptee Antisocial Personality}

\begin{tabular}{lcc} 
Adoptive Mother Age & Absent & Present \\
\hline $21-31$ & $109(89 \%)$ & $13(11 \%)$ \\
$32-47$ & $138(97 \%)$ & $4(3 \%)$ \\
\hline
\end{tabular}

$\chi^{2}(1, \underline{N}=264)=6.69, p=.010 ;$ Fisher's Exact Test $=.009(1$-sided $)$

\section{Adoptee Drug Abuse}

\begin{tabular}{lcc} 
Adoptive Mother Age & Absent & Present \\
\hline $21-31$ & $83(90 \%)$ & $9(10 \%)$ \\
$32-47$ & $105(97 \%)$ & $3(3 \%)$ \\
\hline
\end{tabular}

$\chi^{2}(1, \underline{N}=200)=4.32, p=.038 ;$ Fisher's Exact Test $=.037(1$-sided $)$

\section{Adoptee Alcohol Abuse}

\begin{tabular}{lcc} 
Adoptive Mother Age & Absent & Present \\
\hline $21-31$ & $84(85 \%)$ & $15(15 \%)$ \\
$32-47$ & $107(90 \%)$ & $12(10 \%)$ \\
\hline
\end{tabular}

$\chi^{2}(1, \underline{N}=218)=1.28, \mathrm{p}=.258 ;$ Fisher's Exact Test $=.178(1$-sided $)$

\section{Adoptee Depression}

\begin{tabular}{lcc} 
Adoptive Mother Age & Absent & Present \\
\hline $21-31$ & $87(95 \%)$ & $5(5 \%)$ \\
$32-47$ & $94(87 \%)$ & $14(13 \%)$ \\
\hline
\end{tabular}

$\chi^{2}(1, \underline{N}=200)=3.28, p=.070 ;$ Fisher's Exact Test $=.057(1$-sided $)$ 
Table 4

Adoptive Paternal Age at Adoption and the Development of Psychopathology in Adoptees

Adoptee Antisocial Personality

\begin{tabular}{lcc} 
Adoptive Father Age & Absent & Present \\
\hline $22-30$ & $65(89 \%)$ & $8(11 \%)$ \\
$31-51$ & $169(96 \%)$ & $7(4 \%)$ \\
\hline
\end{tabular}

$\chi^{2}(1, \underline{N}=249)=4.44, \underline{p}=.035 ;$ Fisher's Exact Test $=.039(1$-sided $)$

Adoptee Drug Abuse

\begin{tabular}{lcc} 
Adoptive Father Age & Absent & Present \\
\hline $22-30$ & $49(91 \%)$ & $5(9 \%)$ \\
$31-51$ & $127(96 \%)$ & $6(4 \%)$ \\
\hline
\end{tabular}

$\chi^{2}(1, \underline{N}=187)=1.56, \mathrm{p}=.211 ;$ Fisher's Exact Test $=.180(1$-sided $)$

\section{Adoptee Alcohol Abuse}

\begin{tabular}{lcc} 
Adoptive Father Age & Absent & Present \\
\hline $22-30$ & $48(84 \%)$ & $9(16 \%)$ \\
$31-51$ & $130(89 \%)$ & $16(11 \%)$ \\
\hline
\end{tabular}

$\chi^{2}(1, \underline{N}=203)=0.89, \underline{p}=.347 ;$ Fisher's Exact Test $=.237(1$-sided $)$

\section{$\underline{\text { Adoptee Depression }}$}

\begin{tabular}{lcc} 
Adoptive Father Age & Absent & Present \\
\hline $22-30$ & $54(100 \%)$ & $0(0 \%)$ \\
$31-51$ & $118(89 \%)$ & $15(11 \%)$ \\
\hline
\end{tabular}

$\chi^{2}(1, \underline{N}=187)=6.62, p=.010 ;$ Fisher's Exact Test $=.005(1$-sided $)$ 


\section{References}

Bohman, M., Sigvardsson, S., Cloninger, C.R. (1981). Maternal inheritance of alcohol abuse: Cross-fostering analysis of adopted women. Archives of General Psychiatry, $\underline{38}$, 965-969.

Cadoret, R. J. (1978). Evidence for genetic inheritance of primary affective disorder in adoptees. American Journal of Psychiatry, 135(4), 463-466.

Cadoret, R. J. (1985). Genes, environment and their interaction in the development of psychopathology. In T. Sakai \& T. Tsuboi (Eds): Genetic Aspects of Human Behavior. Igaku-Shoin, Tokyo.

Cadoret, R. J. (1990). Biological perspectives of adoptee adjustment. In D. Brodzinsky \& M. Schechter (Eds): The Psychology of Adoption. Oxford University Press, New York.

Cadoret, R. J. (1992). Genetic and environmental factors in initiation of drug use and the transition to abuse. In Glantz, M. \& Pickens, R. (Eds): Vulnerability to Drug Abuse. American Psychological Institution, Washington, DC.

Cadoret, R. J., Cain, C. A., \& Grove, W. M. (1980). Development of alcoholism in adoptees raised apart from alcoholic biologic relatives. Archives of General Psychiatry. 37, 561-563.

Cadoret, R. J., O'Gorman, T. W., Heywood, E., \& Troughton, E. (1985). Genetic and environmental factors in major depression. Journal of Affective Disorders, 9, 155-164.

Cadoret, R. J., \& Troughton, E. P. (1988). Genetic and environmental factors in alcohol abuse. In Kiianmaa, K., Tabakoff, B., \& Saito, T. (Eds): Genetic Aspects of Alcoholism. The Finnish Foundation for Alcohol Studies, Volume 37. Piscataway, NJ.

Cadoret, R. J., Troughton, E., Bagford, J., \& Woodworth, G. (1990). Genetic and environmental factors in adoptee antisocial personality. European Archives of Psychiatry and Neurological Sciences, 239, 231-240.

Cloninger, C.R., Bohman, M., \& Sigvardsson, S. (1981). Inheritance of alcohol abuse: Cross-fostering analysis of adopted men. Archives of General Psychiatry, 38, 861-868.

Crowe, R. R. (1974). An adoption study of antisocial personality. Archives of General Psychiatry, 31, 785-791. 
Falbo, T., \& Richman, C. L. (1979). Relationships between father's age, birth order, family size, and need achievement. Bulletin of the Psychonomic Society, 13(3), 179182.

Fananas, L., Marti-Tusquets, J. L., \& Bertranpetit, J. (1989). Seasonality of birth in schizophrenia. An insufficient stratification of control population? Social Psychiatry and Psychiatry Epidemiology, 24, 266-270.

Farrer, L., Cupples, A., Connor, L., Wolf, P., \& Growdon, J. H. (1991). Association of decreased paternal age and late-onset Alzheimer's disease. Archives of Neurology, $\underline{48}$, 599-604.

Feighner, J., Robins, E., Guze, S., Woodruff, R., Winokur, G., \& Munoz, R. (1972). Diagnostic criteria for use in psychiatric research. Archives of General Psychiatry, 26, 57-63.

Finley, G. E. (1998a). Parental age and university students' perceptions of parental acceptance-rejection. Interamerican Journal of Psychology, 32(2), 241-244.

Finley, G. E. (1998b). Parental age and parenting quality as perceived by late adolescents. The Journal of Genetic Psychology, 159(4), 505-506.

Finley, G. E., Aguiar, L. J. (1998, November). The effects of children on parents: Adoptee genetic dispositions to psychopathology and psychopathology in the adoptive parent. Poster session presented at the annual conference of the National Council on Family Relations, Milwaukee, WI.

Finley, G. E., Aguiar, L. J. (1999, April). Adoption: Genetic risk for adoptee psychopathology as a function of age of birthfather and birthmother. Poster session presented at the biennial of the Society for Research in Child Development, Albuquerque, NM.

Finley, G. E., Stephenson, D., Williams, S., Janovetz, V. (1993). Father's age and the paternal feelings and attitudes of firsttime fathers. Poster session presented at the Society for Research in Child Development Convention, New Orleans, LA.

Gillberg, C. (1980). Maternal age and infantile autism. Journal of Autism and Developmental Disorders, 10(3), 293-297.

Gillberg, C. (1982). Parental age in child psychiatric clinic attenders. Acta Psychiatric Scandinavia, 66, 471-478.

Goodwin, D. W. (1976). Adoption studies in alcoholism. Journal of Operational Psychiatry, 7(1), 54-63. 
Hare, E. H., \& Moran, P. A. (1979). Raised parental age in psychiatric patients: Evidence for the constitutional hypothesis. British Journal of Psychiatry, 134, 169-177.

Hechtman, L. (1989). Teenage mothers and their children: Risks and problems: A Review. Canadian Journal of Psychiatry, 34, 569-575.

Hofman, A., Van Duijn, C., Schulte, W., Tanja, T., Haaxma, R., Lameris, A., \& Saan, R. J. (1990). Is parental age related to the risk of Alzheimer's disease? British Journal of Psychiatry, 157, 273-275.

Jayasekara, R., \& Street, J. (1978). Parental age and parity in dyslexic boys. Journal of Biosocial Science, 10, 255-261.

Mednick, S. A., Gabrielli, W. F., Jr., \& Hutchings, B. (1984). Genetic influences in criminal convictions: Evidence from an adoption cohort. Science, 224, 891-894.

Mendlewicz, J., \& Rainer, J. (1977). Adoption study supporting genetic transmission in manic-depressive illness. Nature, 268, 327-329.

Merikangas, K. R., Rounsaville, B. J., \& Prusoff, B. A. (1992). Familial factors in vulnerability to substance abuse. In Glantz, M. \& Pickens, R. (Eds): Vulnerability to Drug Abuse. American Psychological Institution, Washington, DC.

Mouridsen, S. E., Rich, B., \& Isager, T. (1993). Brief report: Parental age in infantile autism, autistic-like conditions, and borderline childhood psychosis. Journal of Autism and Developmental Disorders, 23(2), 387-396.

Reich, W., Earls, F., Frankel, O., \& Shayka, J. (1993). Psychopathology in children of alcoholics. Journal of the American Academy of Child and Adolescent Psychiatry, $\underline{32(5)}, 995-1002$.

Roth, W. E., \& Finley, G. E. (1998). Adoption and antisocial personality: Genetic and environmental factors associated with antisocial outcomes. Child and Adolescent Social Work Journal, 15(2), 133-149.

Schuckit, M. A. (1973). Alcoholism and sociopathy: Diagnostic confusion. Quarterly Journal on the Study of Alcoholism, 34, 157-164.

Simonds, J. F., \& Aston, L. (1982). Child psychiatric disorder and behavioral factors related to maternal age at child birth. Journal of Psychiatric Treatment and Evaluation, 4, 129-136.

Urakami, K., Adachi, Y., \& Takahashi, K. (1989). A community-based study of parental age at the birth of patients with dementia of the Alzheimer type. Archives of Neurology, $\underline{46}, 38-39$. 
Winokur, G. (1991). Epidemiology and genetics of depression and mania. In Tsuang, M. T., Kendler, K., \& Lyons, M. J. (Eds): Genetic Issues in Psychosocial Epidemiology. Rutgers University Press. New Brunswick, NJ. 